This manuscript has been published in final form at

https://doi.org/10.1016/j.apsusc.2017.09.181

\title{
OPTICAL, COMPOSITIONAL AND STRUCTURAL PROPERTIES OF PULSED LASER DEPOSITED NITROGEN-DOPED TITANIUM-DIOXIDE
}

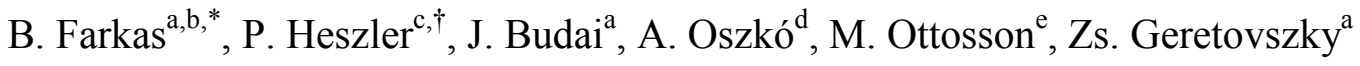

(a) Department of Optics and Quantum Electronics,

University of Szeged, P.O. Box 406, H-6701 Szeged, Hungary

(b) ELI-HU Non-Profit Ltd., Dugonics sq. 13., H-6720 Szeged, Hungary

(c) Research Group on Laser Physics of the Hungarian Academy of Sciences,

University of Szeged, P.O. Box 406, H-6701 Szeged, Hungary

(d) Reaction Kinetics Research Group of the Hungarian Academy of Sciences,

University of Szeged, P.O. Box 168, H-6701 Szeged, Hungary

(e) Department of Chemistry, Angström Laboratory,

Uppsala University, P.O. Box 538, SE-75121 Uppsala, Sweden

* Corresponding author; Tel.: +36 62544 659; Fax: +36 62544 658; E-mail address:

bfarkas@titan.physx.u-szeged.hu (B. Farkas).

$\dagger$ Deceased.

\begin{abstract}
$\mathrm{N}$-doped $\mathrm{TiO}_{2}$ thin films were prepared using pulsed laser deposition by ablating metallic Ti target with pulses of $248 \mathrm{~nm}$ wavelength, at $330{ }^{\circ} \mathrm{C}$ substrate temperature in reactive atmospheres of $\mathrm{N}_{2} / \mathrm{O}_{2}$ gas mixtures. These films were characterized by spectroscopic ellipsometry, X-ray photoelectron spectroscopy and X-ray diffraction. Optical properties are
\end{abstract}


presented as a function of the $\mathrm{N}_{2}$ content in the processing gas mixture and correlated to nitrogen incorporation into the deposited layers. In case of extinction coefficient, refractive index and optical band gap values a monotonically increasing tendency, a maximum and a linearly decreasing slope can be observed with increasing $\mathrm{N}$ concentration, respectively. It is also shown that the amount of substitutional $\mathrm{N}$ can be increased up to 7.7 at. $\%$, but the high dopant concentration inhibits the crystallization of the samples. No peaks of crystalline titanium-nitride were detected despite the large amount of substitutionally incorporated nitrogen.

Keywords: $\mathrm{TiO}_{2-\mathrm{x}} \mathrm{N}_{\mathrm{x}}$; Photocatalytic material; PLD; Ellipsometry; Chemical composition; Structural property

\section{Introduction}

Among numerous oxide materials, titanium-dioxide $\left(\mathrm{TiO}_{2}\right)$ has received unprecedented interest due to its impressive physical and chemical properties that is combined with high stability. These properties have been utilized in various thin film applications, including waveguiding [1], antireflection [2] and anticorrosion [3] coatings; gas sensing [4], microelectronic [5] and biomedical [6] applications. $\mathrm{TiO}_{2}$ has been commonly used as a photocatalytic material $[7,8]$, since the discovery of its photosensitization effect by Honda and Fujisima in 1972 [9]. However, $\mathrm{TiO}_{2}$ has a relatively large band gap (3.2 eV and $3.0 \mathrm{eV}$ for the anatase and rutile phase, respectively) which limits its utilization efficiency to only $4 \%$ of the total solar radiation energy reaching the Earth's surface.

More efficient light utilization can be achieved by reducing the intrinsic band gap of $\mathrm{TiO}_{2}$. Asahi et al. reported [10] that $\mathrm{N}$-doped $\mathrm{TiO}_{2}$ (usually denoted as $\mathrm{TiO}_{2-\mathrm{x}} \mathrm{N}_{\mathrm{x}}$ ) shows a dramatic improvement over undoped $\mathrm{TiO}_{2}$ in its optical absorption and photocatalytic activity for visible (VIS) light that opens up new application areas. The experimental work of 
Nakano et al. [11] supports the idea that the substitutional doping of crystalline $\mathrm{TiO}_{2}$ with nitrogen contributes to band gap narrowing by mixing $2 \mathrm{p}$ states of $\mathrm{N}$ and $\mathrm{O}$. However, there are contradictory theoretical and experimental works. Lee et al. [12] found, using density functional calculations, that bands originating from $\mathrm{N} 2 \mathrm{p}$ states appear in the band gap of $\mathrm{TiO}_{2}$, but their mixing with $\mathrm{O} 2 \mathrm{p}$ states is too weak to produce significant band gap narrowing. Irie et al. [13] reported that the response under VIS light in their $\mathrm{N}$-doped $\mathrm{TiO}_{2}$ samples may be due to isolated $\mathrm{N} 2 \mathrm{p}$ states formed above the valence band maximum of $\mathrm{TiO}_{2}$ rather than the result of band gap narrowing. Kitano et al. [14] attributed the frequently observed weak absorption shoulder in the wavelength range of 400-600 $\mathrm{nm}$ to these isolated N $2 p$ states.

$\mathrm{N}$-doped $\mathrm{TiO}_{2}$ thin films have been prepared by various deposition techniques, including spray pyrolysis [15], sol-gel method [16], atmospheric pressure chemical vapor deposition [17], ion-assisted electron beam evaporation [18], atomic layer deposition [19] and sputtering $[20,21]$. The synthesis of these films by pulsed laser deposition (PLD) was also studied by several groups in the last decade [22-39]. Nitrogen containing titanium-oxide films can easily be made by PLD via varying the experimental conditions, most importantly by ablating different targets $\left(\mathrm{Ti}\right.$ [22-24], $\mathrm{TiO}[24], \mathrm{TiO}_{2}$ [24-33], $\mathrm{TiN}[24,34]$, pre-mixed $\left(\mathrm{TiO}_{2}+\mathrm{TiN}\right)$ $[35,36]$ and TiNO [37]) in a variety of atmospheres $\left(\mathrm{N}_{2}\right.$ [25-27], $\mathrm{O}_{2}[34,35], \mathrm{NH}_{3}[28], \mathrm{N}_{2} \mathrm{O}$ [29], $\mathrm{N}_{2} / \mathrm{O}_{2}$ [22-24, 31-33, 36], $\mathrm{NH}_{3} / \mathrm{N}_{2} / \mathrm{O}_{2}$ [22] or $\mathrm{N}_{2} / \mathrm{O}_{2} / \mathrm{CH}_{4}$ [33]). Alternatively, postprocessing of a $\mathrm{TiO}_{2}$ film via e.g. subsequent calcination in $\mathrm{N}_{2}$ or $\mathrm{NH}_{3}$ atmospheres [38] or Nion bombardment [39] can also be used for nitrogen incorporation. Despite these efforts, the effect of $\mathrm{N}$-doping on the optical properties of $\mathrm{TiO}_{2}$ is still under debate.

Spectroscopic ellipsometry (SE) is a fast and non-destructive method used to determine the dispersion of the optical properties of materials and thickness of thin films. This technique, with concomitant compositional and structural analysis allows for the in-depth 
characterization of $\mathrm{N}$-doped $\mathrm{TiO}_{2}$ thin films and to compare and correlate the full optical properties of these films to their chemical composition and structure.

Here we report our results on the spectroscopic ellipsometry, X-ray photoelectron spectroscopy (XPS) and X-ray diffraction (XRD) analysis of $\mathrm{TiO}_{2}$ and $\mathrm{N}$-doped $\mathrm{TiO}_{2}$ films grown in $\mathrm{N}_{2} / \mathrm{O}_{2}$ gas mixtures of various compositions at substrate temperature of $330{ }^{\circ} \mathrm{C}$ in a conventional PLD setup. We will demonstrate and discuss the effect of $\mathrm{N}_{2}$ concentration in the processing gas mixture on the refractive index, extinction coefficient, band gap, extent of nitrogen incorporation and crystal structure of the deposited samples.

\section{Experimental}

The experimental setup has been previously reported [23] and thus only a brief recapitulation is provided here. $\mathrm{A} \mathrm{KrF}$ excimer laser $(\lambda=248 \mathrm{~nm}, \tau=15 \mathrm{~ns})$ was used to ablate Ti targets (99.6\% purity). The pulse energy at the target surface was kept constant at $40 \mathrm{~mJ}$. The measured laser fluence decreased during growth runs from 7.2 to $3.8 \mathrm{~J} / \mathrm{cm}^{2}$. This reduction was due to the steady enlargement of ablation craters caused by the repetitive illumination of the target surface with laser pulses of inhomogeneous intensity distribution (Gaussian and super-Gaussian along its two major axes) [40]. Fused silica substrates were placed $4.5 \mathrm{~cm}$ away from the target in a traditional, on-axis PLD geometry. Depositions were made at $330{ }^{\circ} \mathrm{C}$ substrate temperature in either high purity $\mathrm{O}_{2}$ gas $(99.998 \%)$ or in a mixture of high purity $\mathrm{N}_{2}(99.999 \%)$ and $\mathrm{O}_{2}$ gas and the total pressure was kept constant at $5 \mathrm{~Pa}$.

Optical characterization of the as grown layers was made by variable angle spectroscopic ellipsometry. The $\Psi$ and $\Delta$ values were measured in the $245-1000 \mathrm{~nm}$ spectral range with a Woollam M-2000F rotating compensator variable angle spectroscopic ellipsometer in microspot mode at four different angles of incidence (50-65 $)$. The layers' optical properties were determined from the ellipsometric data using a recently published ellipsometric analysis 
method, called automated artifact minimization method (A2M2) [41]. This method allows for the determination of the wavelength dependent complex dielectric function of the examined material without the need of the mathematical description of the optical properties' dispersion, which makes it useful, especially for newly developed materials like $\mathrm{N}$-doped $\mathrm{TiO}_{2}$. The A2M2 is based on the observation that Kramers-Kronig consistency of numerically inverted dielectric curves is lost if interference related artifacts are present in the numerically inverted dielectric function. The Kramers-Kronig consistency is quantified by using the self consistency curve (SCC), which is defined as the difference of the real and the KramersKronig integrated imaginary parts of the dielectric function. By defining the root mean square value of the SCC as $R M S=\sqrt{\frac{1}{M} \cdot \sum_{j=1}^{M}\left(S C C^{j}\right)^{2}}$, where $S C C^{\mathrm{j}}$ denotes the $j^{\text {th }}$ point of the self consistency curve and $M$ is the number of photon energies at which the Kramers-Kronig integral is evaluated, the optimization with respect to Kramers-Kronig consistency is equivalent to finding the $\varepsilon_{1}, \varepsilon_{2}$ curve pair exhibiting the smallest RMS value.

In order to determine the amount and the chemical environment of the different elements in the deposited films, XPS measurements were carried out by using a SPECS instrument equipped with a PHOIBOS 150 MCD-9 hemispherical electron energy analyzer operated in the FAT mode. The excitation source was the non-monochromatic $\mathrm{K}_{\alpha}$ radiation from a magnesium anode $(\mathrm{h} v=1253.6 \mathrm{eV})$ operated at $225 \mathrm{~W}$ power $(15 \mathrm{kV}, 15 \mathrm{~mA})$. The incident angle of the X-ray beam was $45^{\circ}$ with respect to the surface normal. The pass energy was set to $20 \mathrm{eV}$, the step size was $25 \mathrm{meV}$ and the acquisition time in one channel was $100 \mathrm{~ms}$. The C 1s binding energy of adventitious carbon $(285.1 \mathrm{eV})$ was used as energy reference. The manufacturer's SpecsLab2 and further commercial software packages (CasaXPS, Origin) were used for data acquisition and evaluation, respectively. Curve fittings were performed after Shirley background subtraction by using Gaussian-Lorentzian product functions with mixing ratio of $0.7(1.0=$ pure Gaussian, $0.0=$ pure Lorentzian $)$. 
To investigate the crystal structure of the deposited films, XRD measurements were performed by using a Philips MRD diffractometer in parallel beam configuration using a Ni-C X-ray mirror as primary optics and a $0.27^{\circ}$ parallel plate collimator as secondary optics. The $\mathrm{Cu} \mathrm{K} \mathrm{K}_{\alpha}$ radiation source was operated at $45 \mathrm{kV}$ and $40 \mathrm{~mA}$. A grazing incidence of $3^{\circ}$ was used due to the small thickness of the grown layers. The $2 \theta$ scans were carried out in the range of $20-70^{\circ}$. The peak widths were obtained by fitting in the X'pert HighScore Plus program from PANanalytical using pseudo-Voigt profile functions.

\section{Results and Discussion}

The optical properties of $\mathrm{N}$-doped $\mathrm{TiO}_{2}$ films were determined from the ellipsometric data using the A2M2 [41]. The essence of the A2M2 is to automate the selection of artifact free $\varepsilon_{1}, \varepsilon_{2}$ curves in an objective manner, based on the Kramers-Kronig consistency of numerically inverted dielectric curves. The procedure starts with the definition of an ellipsometric model of the sample with the number and type of layers and the optical properties of known layers. The initial value of the layer thicknesses is then set and an exact numerical inversion is performed [42]. Last, the thickness of each layer is varied and numerical inversion is repeated until artifact free $\varepsilon_{1}, \varepsilon_{2}$ curves exhibiting the SCC of the smallest RMS value are obtained.

Our samples were described by a three layer model (fused silica substrate/ $\mathrm{TiO}_{2}$ or $\mathrm{N}$-doped $\mathrm{TiO}_{2}$ layer/surface roughness). The refractive index and extinction coefficient of the substrate were determined in a separate ellipsometric measurement, while the optical properties of the roughness layer were estimated by the Bruggeman effective medium approximation, assuming 50\% void content. In some cases in-depth gradient was assumed in the dielectric constant of the unknown layer. The effect of absorption outside the measured spectral range was taken into account by using an integration constant and two Sellmeier oscillators and the SCC was normalized to the absolute value of the dielectric function at each wavelength [43]. 
Fig. 1a shows measured and fitted $\Psi$ and $\Delta$ curves of a $\mathrm{N}$-doped $\mathrm{TiO}_{2}$ sample deposited in a gas mixture of $10 \mathrm{v} / \mathrm{v} \% \mathrm{~N}_{2}$ content. The measured ellipsometric data is well fitted with the A2M2. The $\varepsilon_{2}$ curve (solid line) is plotted for the low absorption spectral range in Fig. 1b. In addition, interference-related artifacts are also demonstrated when, for example, the thickness of the roughness layer is not correctly chosen. As it is shown, even a $\pm 0.5 \mathrm{~nm}$ difference in the thickness of the roughness layer makes these artifacts clearly visible, demonstrating the high accuracy of the method. Fig. 1c shows the numerically inverted $\varepsilon_{l}$ curve (solid black) and the Kramers-Kronig integrated one (dashed gray) for the optimum film and surface roughness thicknesses, $107.4 \pm 0.3 \mathrm{~nm}$ and $3.4 \pm 0.2 \mathrm{~nm}$, respectively. The confidence intervals have been estimated on the basis of what change in the film and surface roughness thickness caused maximum $20 \%$ difference in the RMS belonging to the optimum thickness values. The inset of Fig. 1c represents the corresponding normalized SCC. The calculated RMS map and its minimum (indicated by the cross hair) are shown in Fig. 1d.

From the real and imaginary parts of the dielectric function the refractive index and extinction coefficient can be derived by the $n=\sqrt{\left(\sqrt{\varepsilon_{1}^{2}+\varepsilon_{2}^{2}}+\varepsilon_{1}\right) / 2}$ and $k=\sqrt{\left(\sqrt{\varepsilon_{1}^{2}+\varepsilon_{2}^{2}}-\varepsilon_{1}\right) / 2}$ formulae, respectively, while the absorption coefficient can be computed from the extinction coefficient using the $\alpha=4 \pi k / \lambda$ relationship. Fig. 2 demonstrates the effect of $\mathrm{N}_{2}$ concentration in the processing gas mixture on the optical properties of the deposited films. Error bars were determined based on the confidence intervals of the film thicknesses. Fig. 2a presents the dispersion of the absorption coefficient for pure $\mathrm{TiO}_{2}$ and three $\mathrm{N}$-doped $\mathrm{TiO}_{2}$ films, while Fig. $2 b$ shows the extinction coefficient and refractive index values of all samples at $480 \mathrm{~nm}$, roughly where the solar irradiance peaks. It can be seen that the higher the $\mathrm{N}_{2}$ content of the $\mathrm{N}_{2} / \mathrm{O}_{2}$ gas mixture, the larger the VIS absorption of the samples, whilst the refractive index exhibits a maximum as a function of the $\mathrm{N}_{2}$ concentration. The latter tendency is in line with earlier results in which a monotonically increasing [20] and 
decreasing [18] tendency was reported at smaller and larger nitrogen contents, respectively.

Since nitrogen has a greater atomic radius than oxygen, the increased refractive index at lower $\mathrm{N}_{2}$ concentrations is attributed to the density increase of the deposited films, which is in turn due to the (expected and below confirmed) increasing amount of substitutionally incorporated nitrogen. The drop in the refractive index observed at higher $\mathrm{N}_{2}$ concentrations is most probably caused by the increasingly dominant infrared absorption (see Fig. 2a). Although the large amount of substitutionally incorporated nitrogen, the refractive index decrease and the intensifying infrared absorption all point to the possible formation of titanium-nitride (TiN), the XRD results did not confirm this (see below).

The band gap energy of indirect semiconductors, such as $\mathrm{TiO}_{2}$ [44] and $\mathrm{N}$-doped $\mathrm{TiO}_{2}$ [45], can be derived from the intercept of the tangent fitted to the $(\alpha h v)^{1 / 2} v s h v$ plot. Fig. 2c presents evaluated band gap energies for the $\mathrm{TiO}_{2}$ and $\mathrm{N}$-doped $\mathrm{TiO}_{2}$ films. As we can see, the higher the $\mathrm{N}_{2}$ content of the $\mathrm{N}_{2} / \mathrm{O}_{2}$ gas mixture, the lower the optical band gap. The extent of band gap narrowing is in good agreement with the work of Sauthier et al. [32], who used pressed $\mathrm{TiO}_{2}$ powder targets and were able to incorporate considerably lower amount of nitrogen ( $\leq 2.8$ at. $\%$ in total, i.e. chemisorbed and bonded). The observed inverse correlation is attributed to the increasing nitrogen incorporation, particularly substitutional nitrogen, into the deposited layers, which leads to the shift of the absorption edge to lower photon energies with increasing $\mathrm{N}_{2}$ concentration. In order to test this hypothesis, XPS measurements were performed.

The overview XPS spectra proved that the surface of the samples is composed of $\mathrm{Ti}, \mathrm{O}$ and $\mathrm{N}$ with traces of adventitious C. High resolution Ti $2 \mathrm{p}$ spectra showed two peaks, centered around $458.4 \mathrm{eV}$ and $464.1 \mathrm{eV}$ corresponding to Ti $2 \mathrm{p}_{3 / 2}$ and Ti $2 \mathrm{p}_{1 / 2}$, respectively, indicating that titanium is present in the form of $\mathrm{Ti}^{4+}$. High resolution $\mathrm{O} 1 \mathrm{~s}$ spectra showed a strong peak with a shoulder on the high binding energy side, which could be deconvolved into two or (for some of the doped films) three components. The strong peak at binding energy of $529.9 \mathrm{eV}$ is 
assigned to oxygen in the form of $\mathrm{O}^{2-}$, the second peak at $531.4 \mathrm{eV}$ to hydroxide groups $(\mathrm{OH})$, while the third one at $532.5 \mathrm{eV}$ is attributed to oxygen in either an $\mathrm{O}=\mathrm{C}$ or $\mathrm{C}-\mathrm{O}-\mathrm{C}$ chemical environment [46].

Fig. 3a shows high resolution $\mathrm{N}$ 1s XPS spectra of an undoped and a highly $\mathrm{N}$-doped $\mathrm{TiO}_{2}$ film. The peak at binding energy of $399.8 \mathrm{eV}$ in the spectrum of the $\mathrm{TiO}_{2}$ film is attributed to $\mathrm{N}-\mathrm{N}, \mathrm{N}-\mathrm{O}$ and $\mathrm{N}-\mathrm{C}$ bondings [47]. In addition, the $\mathrm{N}$-doped films exhibit a further peak at $395.8 \mathrm{eV}$, which is assigned to $\mathrm{Ti}-\mathrm{N}$ bonding (substitutional nitrogen) [48, 49]. It should be noted that in case of the $\mathrm{N}$-doped films a slight downshift in the position of the Ti $2 \mathrm{p}_{3 / 2}$ peak was observed, as compared to the undoped $\mathrm{TiO}_{2}$ case, which further strengthens our conclusion on the existence of Ti-N bondings in these films. After deconvolution of the high resolution XPS spectra, the amount of substitutional $\mathrm{N}$ was estimated by taking into account the equipment's sensitivity factors for the different elements and comparing the areas under the substitutional $\mathrm{N}$ peak $(395.8 \mathrm{eV})$ to that of the Ti $2 \mathrm{p}_{3 / 2}$ peak $(458.4 \mathrm{eV})$. Error bars were calculated from the uncertainties of the peak fittings by using error propagation. The inset of Fig. 3a clearly demonstrates that the extent of substitution of nitrogen into the lattice oxygen positions of $\mathrm{TiO}_{2}$ can be controlled by changing the concentration of the $\mathrm{N}_{2}$ gas in the processing gas mixture. The amount of substitutional $\mathrm{N}$ increased from 0 to values as high as 7.7 at. $\%$ whilst the $\mathrm{N}_{2}$ content of the $\mathrm{N}_{2} / \mathrm{O}_{2}$ gas mixture increased from 0 to $90 \mathrm{v} / \mathrm{v} \%$. In Fig. $3 \mathrm{~b}$ the band gap values of the $\mathrm{TiO}_{2}$ and $\mathrm{N}$-doped $\mathrm{TiO}_{2}$ samples are plotted as a function of the atomic percentage of substitutional N. As we can see, there is a linear correlation between these two quantities. This proves that the substitutional $\mathrm{N}$ is indeed responsible for the shift of the absorption edge to lower photon energies and for the decreasing of the band gap, supporting the assumption of Asahi et al. [10]. This linear correlation prove again the versatility of ellipsometry, namely that one can get access to other physical properties via probing the complex dielectric function. 
The crystalline structure of the deposited films was investigated by XRD. Fig. 4 presents the XRD patterns of the $\mathrm{TiO}_{2}$ and three $\mathrm{N}$-doped $\mathrm{TiO}_{2}$ samples deposited in $\mathrm{N}_{2} / \mathrm{O}_{2}$ gas mixtures of different composition. The XRD diffractograms of the $\mathrm{N}$-doped $\mathrm{TiO}_{2}$ samples show no specific peaks of TiN, e.g. at $2 \theta=36.6^{\circ}, 42.7^{\circ}$ or $61.4^{\circ}$ corresponding to the (111), (200) and (220) planes, respectively [50], despite the substantial nitrogen incorporation into the films. The crystallization of the samples also decreased with increasing $\mathrm{N}_{2}$ concentration in the growth ambient. The films deposited in pure oxygen atmosphere and at low nitrogen concentrations consist of anatase phases of $\mathrm{TiO}_{2}$, while the films obtained at high nitrogen concentrations, i.e. above $50 \mathrm{v} / \mathrm{v} \% \mathrm{~N}_{2}$ content of the $\mathrm{N}_{2} / \mathrm{O}_{2}$ gas mixture, exhibit amorphous structure. The crystallite size for the former cases was estimated from the broadening of the highest intensity anatase (101) diffraction peak by applying the Scherrer formula. It was found that the anatase crystallite size decreases with increasing $\mathrm{N}_{2}$ concentration in the processing gas mixture. Namely it decreased from about $850 \AA$ to $630 \AA$ whilst the $\mathrm{N}_{2}$ content increased from 0 to $20 \mathrm{v} / \mathrm{v} \%$.

This amorphization or inhibition effect with increasing $\mathrm{N}_{2}$ concentration differs from previous results. For example, Matsui et al. [30] reported that the full width half maximum of the diffraction peaks' were almost independent of the incorporated nitrogen concentration, while Xu et al. [22] reported that no significant change in the crystalline structure could be observed as a function of N-doping, although they used glass substrates instead of close lattice matched $\mathrm{LaAlO}_{3}$. Zhao et al. [26] showed that N-doping changed the films' anatase structure from (004) preferred orientation to random. Duta et al. [27] found that the width of the (101) line in the $\mathrm{N}$-doped film broadened as compared to undoped $\mathrm{TiO}_{2}$ and linked nitrogen incorporation to a reduction in crystallization. Somekawa et al. [25] saw a rutile-anatase, while Delegan et al. [21] an anatase-rutile- $\mathrm{TiO}_{2}: \mathrm{N}$ phase transition. Sauthier et al. [31] experienced that the typical anatase $\mathrm{TiO}_{2} \mathrm{X}$-ray diffraction peaks changed to lattice plane reflections of the monoclinic $\mathrm{TiO}_{0.34} \mathrm{~N}_{0.74}$ phase. Suda et al. [24] showed that the intensity of the detected 
anatase crystalline peaks decreased as the $\mathrm{N}_{2}$ concentration in the $\mathrm{N}_{2} / \mathrm{O}_{2}$ gas mixture increased and the deposited layer become amorphous in a pure $\mathrm{N}_{2}$ atmosphere. However, $\mathrm{N} 1 \mathrm{~s}$ peaks in the XPS spectra could not be detected in these films grown from $\mathrm{TiO}_{2}$ target meaning that the crystalline structure of these samples depended solely on the $\mathrm{N}_{2}$ concentration of the applied gas atmosphere. In our films, substitutional nitrogen is present and its amount increases with increasing $\mathrm{N}_{2}$ concentration of the processing gas mixture. We strongly believe that the observed inhibition effect cannot be solely an effect of the background gas composition, but this behavior must have a chemical aspect as well.

\section{Conclusions}

$\mathrm{TiO}_{2}$ and $\mathrm{N}$-doped $\mathrm{TiO}_{2}$ films have been prepared at $330{ }^{\circ} \mathrm{C}$ substrate temperature from metallic Ti target in various reactive $\left(\mathrm{N}_{2}+\mathrm{O}_{2}\right)$ gas atmospheres using pulsed laser deposition technique. It has been demonstrated that the extent of substitutional nitrogen can be readily controlled by changing the concentration of the $\mathrm{N}_{2}$ in the processing gas mixture and can be increased up to 7.7 at.\%. The optical properties of the deposited films were determined using the automated artifact minimization method. It has been shown that increasing $\mathrm{N}_{2}$ content of the background gas mixture results in a steady and significant decrease in the optical band gap and a concomitant increase in the extinction coefficient/VIS absorption, while there is a maximum in the refractive index around $65 \mathrm{v} / \mathrm{v} \% \mathrm{~N}_{2}$ content. The observed tendencies were attributed to the increasing amount of substitutional nitrogen in the grown layers, as determined by XPS, and the increase in the density of the deposited films. Despite the high levels of N-doping, no diffraction peaks of crystalline TiN were detected. The films deposited in pure oxygen atmosphere and at low nitrogen concentrations consisted of anatase phases of $\mathrm{TiO}_{2}$ and the crystallite size decreased with increasing $\mathrm{N}_{2}$ concentration in the processing gas mixture, while the films obtained at high nitrogen concentrations exhibited amorphous 
structure. These observations, together with the compositional analysis, support the idea that high N-dopant concentration can inhibit the crystallization of the samples.

\section{Acknowledgement}

The financial support of the Hungarian Scientific Research Fund under contract numbers OTKA TS 049872 and NKTH-OTKA CNK 78549 is kindly acknowledged.

\section{References}

[1] T. Touam, L. Znaidi, D. Vrel, I. Ninova-Kuznetsova, O. Brinza, A. Fischer, A. Boudrioua, Low loss sol-gel $\mathrm{TiO}_{2}$ thin films for waveguiding applications, Coatings 3 (2013) 49-58.

[2] N.H. Arabi, A. Iratni, H. El Hamzaoui, B. Capoen, M. Bouazaoui, M. Halbwax, J.P. Vilcot, S. Bastide, Antireflective sol-gel $\mathrm{TiO}_{2}$ thin films for single crystal silicon and textured polycrystal silicon, J. Sol-Gel Sci. Technol. 62 (2012) 24-30.

[3] A. Giardini-Guidoni, V. Marotta, R. Teghil, T.M. Di Palma, A.M. Beccaria, L. Chiaruttini, Anticorrosion titanium oxide coatings deposited by pulsed laser ablation, Surf. Coat. Technol. 100-101 (1998) 437-439.

[4] E. György, G. Socol, E. Axente, I.N. Mihailescu, C. Ducu, S. Ciuca, Anatase phase $\mathrm{TiO}_{2}$ thin films obtained by pulsed laser deposition for gas sensing applications, Appl. Surf. Sci. 247 (2005) 429-433.

[5] K. Vydianathan, G. Nuesca, G. Peterson, E.T. Eisenbraun, A.E. Kaloyeros, J.J. Sullivan, B. Han, Metalorganic chemical vapor deposition of titanium oxide for microelectronics applications, J. Mater. Res. 16 (2001) 1838-1849. 
[6] Z.F. Yin, L. Wu, H.G. Yang, Y.H. Su, Recent progress in biomedical applications of titanium dioxide, Phys. Chem. Chem. Phys. 15 (2013) 4844-4858.

[7] A.L. Linsebigler, G. Lu, J.T. Yates Jr., Photocatalysis on $\mathrm{TiO}_{2}$ Surfaces: Principles, Mechanisms and Selected Results, Chem. Rev. 95 (1995) 735-758.

[8] J. Schneider, M. Matsuoka, M. Takeuchi, J. Zhang, Y. Horiuchi, M. Anpo, D.W. Bahnemann, Understanding $\mathrm{TiO}_{2}$ Photocatalysis: Mechanisms and Materials, Chem. Rev. 114 (2014) 9919-9986.

[9] A. Fujishima, K. Honda, Electrochemical Photolysis of Water at a Semiconductor Electrode, Nature 238 (1972) 37-38.

[10] R. Asahi, T. Morikawa, T. Ohwaki, K. Aoki, Y. Taga, Visible-light photocatalysis in nitrogen-doped titanium oxides, Science 393 (2001) 269-271.

[11] Y. Nakano, T. Morikawa, T. Ohwaki, Y. Taga, Deep-level optical spectroscopy investigation of $\mathrm{N}$-doped $\mathrm{TiO}_{2}$ films, Appl. Phys. Lett. 86 (2005) 132104.

[12] J.-Y. Lee, J. Park, J.-H. Cho, Electronic properties of N- and C-doped $\mathrm{TiO}_{2}$, Appl. Phys. Lett. 87 (2005) 011904.

[13] H. Irie, Y. Watanabe, K. Hashimoto, Nitrogen-concentration dependence on photocatalytic activity of $\mathrm{TiO}_{2-x} \mathrm{~N}_{x}$ powders, J. Phys. Chem. B 107 (2003) 5483-5486.

[14] M. Kitano, K. Funatsu, M. Matsuoka, M. Ueshima, M. Anpo, Preparation of nitrogensubstituted $\mathrm{TiO}_{2}$ thin film photocatalysts by the radio frequency magnetron sputtering deposition method and their photocatalytic reactivity under visible light irradiation, J. Phys. Chem. B 110 (2006) 25266-25272. 
[15] D. Li, H. Haneda, S. Hishita, N. Ohashi, Visible-light-driven nitrogen-doped $\mathrm{TiO}_{2}$ photocatalysts: effect of nitrogen precursors on their photocatalysis for decomposition of gasphase organic pollutants, Mater. Sci. Eng. B 117 (2005) 67-75.

[16] N. Venkatachalam, A. Vinu, S. Anandan, B. Arabindoo, V. Murugesan, Visible light active photocatalytic degradation of bisphenol-A using nitrogen doped $\mathrm{TiO}_{2}$, J. Nanosci. Nanotechnol. 6 (2006) 2499-2507.

[17] Y. Guo, X.W. Zhang, G.R. Han, Investigation of structure and properties of N-doped $\mathrm{TiO}_{2}$ thin films grown by APCVD, Mater. Sci. Eng. B 135 (2006) 83-87.

[18] P.-G. Wu, C.-H. Ma, J.K. Shang, Effects of nitrogen doping on optical properties of $\mathrm{TiO}_{2}$ thin films, Appl. Phys. A 81 (2005) 1411-1417.

[19] V. Pore, M. Heikkila, M. Ritala, M. Leskela, S. Areva, Atomic layer deposition of $\mathrm{TiO}_{2-}$ ${ }_{x} \mathrm{~N}_{\mathrm{x}}$ thin films for photocatalytic applications, J. Photochem. Photobiol. A 177 (2006) 68-75.

[20] G. He, L.D. Zhang, G.H. Li, M. Liu and X.J. Wang, Structure, composition and evolution of dispersive optical constants of sputtered $\mathrm{TiO}_{2}$ thin films: effects of nitrogen doping, J. Phys. D: Appl. Phys. 41 (2008) 045304.

[21] N. Delegan, R. Daghrir, P. Drogui, M.A. El Khakani, Bandgap tailoring of in-situ nitrogen-doped $\mathrm{TiO}_{2}$ sputtered films intended for electrophotocatalytic applications under solar light, J. Appl. Phys. 116 (2014) 153510.

[22] P. Xu, L. Mi, P.-N. Wang, Improved optical response for $\mathrm{N}$-doped anatase $\mathrm{TiO}_{2}$ films prepared by pulsed laser deposition in $\mathrm{N}_{2} / \mathrm{NH}_{3} / \mathrm{O}_{2}$ mixture, J. Cryst. Growth 289 (2006) 433439.

[23] B. Farkas, J. Budai, I. Kabalci, P. Heszler, Zs. Geretovszky, Optical characterization of PLD grown nitrogen-doped $\mathrm{TiO}_{2}$ thin films, Appl. Surf. Sci. 254 (2008) 3484-3488. 
[24] Y. Suda, H. Kawasaki, T. Ueda, T. Ohshima, Preparation of nitrogen-doped titanium oxide thin film using a PLD method as parameters of target material and nitrogen concentration ratio in nitrogen/oxygen gas mixture, Thin Solid Films 475 (2005) 337-341.

[25] S. Somekawa, Y. Kusumoto, M. Ikeda, B. Ahmmad, Y. Horie, Fabrication of N-doped $\mathrm{TiO}_{2}$ thin films by laser ablation method: Mechanism of $\mathrm{N}$-doping and evaluation of the thin films, Catal. Commun. 9 (2008) 437-440.

[26] L. Zhao, Q. Jiang, J. Lian, Visible-light photocatalytic activity of nitrogen-doped $\mathrm{TiO}_{2}$ thin film prepared by pulsed laser deposition, Appl. Surf. Sci. 254 (2008) 4620-4625.

[27] L. Duta, C. Popescu, A. Popescu, M. Motoc, C. Logofatu, A. Enesca, A. Duta, E. György, Nitrogen-doped and gold-loaded $\mathrm{TiO}_{2}$ photocatalysts synthesized by sequential reactive pulsed laser deposition, Appl. Phys. A: Mater. 117 (2014) 97-101.

[28] N. Sato, M. Matsuda, M. Yoshinaga, T. Nakamura, S. Sato, A. Muramatsu, The Synthesis and Photocatalytic Properties of Nitrogen Doped $\mathrm{TiO}_{2}$ Films Prepared Using the AC-PLD Method, Top. Catal. 52 (2009) 1592-1597.

[29] N.N. Bao, H.M. Fan, J. Ding, J.B. Yi, Room temperature ferromagnetism in N-doped rutile $\mathrm{TiO}_{2}$ films, J. Appl. Phys. 109 (2011) $07 \mathrm{C} 302$.

[30] H. Matsui, H. Tabata, N. Hasuike, H. Harima, B. Mizobuchi, Epitaxial growth and characteristics of $\mathrm{N}$-doped anatase $\mathrm{TiO}_{2}$ films grown using a free-radical nitrogen oxide source, J. Appl. Phys. 97 (2005) 123511.

[31] G. Sauthier, E. György, A. Figueras, Investigation of nitrogen-doped $\mathrm{TiO}_{2}$ thin films grown by reactive pulsed laser deposition, J. Mater. Res. 23 (2008) 2340-2345. 
[32] G. Sauthier, F.J. Ferrer, A. Figueras, E. György, Growth and characterization of nitrogen-doped $\mathrm{TiO}_{2}$ thin films prepared by reactive pulsed laser deposition, Thin Solid Films 519 (2010) 1464-1469.

[33] G. Socol, Y. Gnatyuk, N. Stefan, N. Smirnova, V. Djokic, C. Sutan, V. Malinovschi, A. Stanculescu, O. Korduban, I.N. Mihailescu, Photocatalytic activity of pulsed laser deposited $\mathrm{TiO}_{2}$ thin films in $\mathrm{N}_{2}, \mathrm{O}_{2}$ and $\mathrm{CH}_{4}$, Thin Solid Films 518 (2010) 4648-4653.

[34] T.L. Chen, Y. Hirose, T. Hitosugi, T. Hasegawa, One unit-cell seed layer induced epitaxial growth of heavily nitrogen doped anatase $\mathrm{TiO}_{2}$ films, J. Phys. D: Appl. Phys. 41 (2008) 062005.

[35] T. Okato, T. Sakano, M. Obara, Suppression of photocatalytic efficiency in highly Ndoped anatase films, Phys. Rev. B 72 (2005) 115124.

[36] J. Hu, H. Tang, X. Lin, Z. Luo, H. Cao, Q. Li, Y. Liu, J. Long, P. Wang, Doped Titanium Dioxide Films Prepared by Pulsed Laser Deposition Method, Int. J. Photoenergy 2012 (2012) 758539.

[37] H. Do, Y.-H. Wu, V.-T. Dai, C.-Y. Peng, T.-C. Yen, L. Chang, Structure and property of epitaxial titanium oxynitride grown on $\mathrm{MgO}(001)$ substrate by pulsed laser deposition, Surf. Coat. Technol. 214 (2013) 91-96.

[38] L. Mi, P. Xu, P.-N. Wang, Experimental study on the bandgap narrowings of $\mathrm{TiO}_{2}$ films calcined under $\mathrm{N}_{2}$ or $\mathrm{NH}_{3}$ atmosphere, Appl. Surf. Sci. 255 (2008) 2574-2580.

[39] H. Shen, L. Mi, P. Xu, W. Shen, P.-N. Wang, Visible-light photocatalysis of nitrogendoped $\mathrm{TiO}_{2}$ nanoparticulate films prepared by low-energy ion implantation, Appl. Surf. Sci. 253 (2007) 7024-7028. 
[40] B. Farkas, Zs. Geretovszky, On determining the spot size for laser fluence measurements, Appl. Surf. Sci. 252 (2006) 4728-4732.

[41] J. Budai, B. Farkas, Z.L. Horváth, Zs. Geretovszky, On determining the optical properties and layer structure from spectroscopic ellipsometric data using automated artifact minimization method, Thin Solid Films 567 (2014) 14-19.

[42] Harland G. Tompkins, Eugene A. Irene (Eds.), Handbook of Ellipsometry, William Andrew Publishing \& Springer-Verlag, Norwich, New York, 2005.

[43] C.M. Herzinger, P.G. Snyder, B. Johs, J.A. Woollam, InP optical constants between 0.75 and $5.0 \mathrm{eV}$ determined by variable-angle spectroscopic ellipsometry, J. Appl. Phys. 77 (1995) $1715-1724$.

[44] N. Daude, C. Gout, C. Jouanin, Electronic band structure of titanium dioxide, Phys. Rev. B 15 (1977) 3229-3235.

[45] H. Gao, J. Zhou, D. Dai, Y. Qu, Photocatalytic activity and electronic structure analysis of $\mathrm{N}$-doped anatase $\mathrm{TiO}_{2}$ : a combined experimental and theoretical study, Chem. Eng. Technol. 32 (2009) 867-872.

[46] L. Körösi, Sz. Papp, I. Bertóti, I. Dékány, Surface and bulk composition, structure, and photocatalytic activity of phosphate-modified $\mathrm{TiO}_{2}$, Chem. Mater. 19 (2007) 4811-4819.

[47] Aracely Hernández-Ramírez, Iliana Medina-Ramírez (Eds.), Photocatalytic Semiconductors: Synthesis, Characterization and Environmental Applications, Springer International Publishing, Cham, Switzerland, 2015.

[48] T. Morikawa, R. Asahi, T. Ohwaki, K. Aoki, Y. Taga, Band-gap narrowing of titanium dioxide by nitrogen doping, Jpn. J. Appl. Phys. 40 (2001) L561-L563. 
[49] N.T. Nolan, D.W. Synnott, M.K. Seery, S.J. Hinder, A. Van Wassenhoven, S.C. Pillai, Effect of N-doping on the photocatalytic activity of sol-gel $\mathrm{TiO}_{2}$, J. Hazard. Mater. 211-212 (2012) 88-94.

[50] S.H. Kim, H. Park, K.H. Lee, S.H. Jee, D.-J. Kim, Y.S. Yoon, H.B. Chae, Structure and mechanical properties of titanium nitride thin films grown by reactive pulsed laser deposition, J. Ceram. Process. Res. 10 (2009) 49-53. 


\section{Figures}
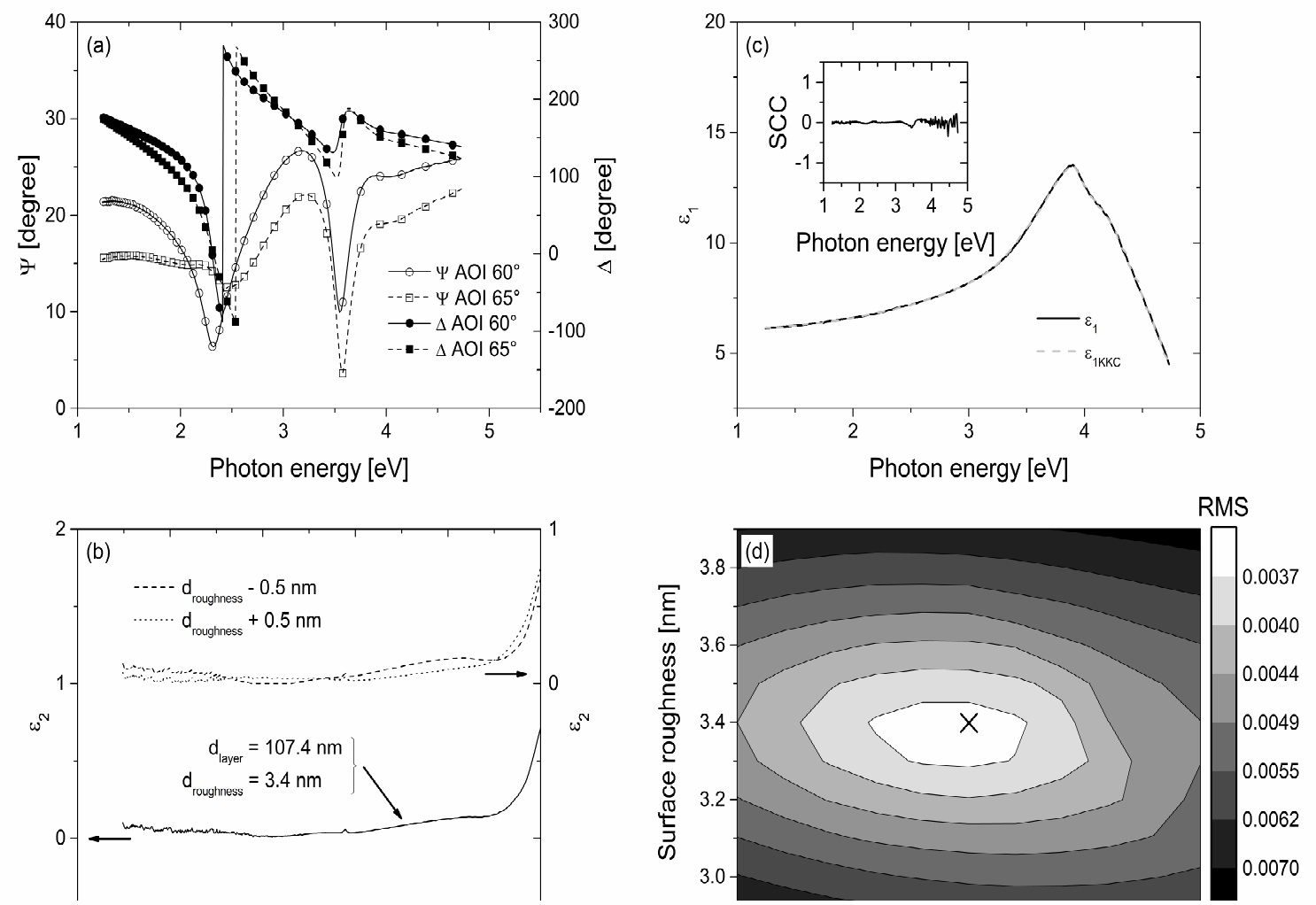

Fig. 1. (a) Measured (symbols) and fitted (lines) $\Psi$ and $\Delta$ values for the film deposited at $330{ }^{\circ} \mathrm{C}$ substrate temperature in a gas mixture of $10 \mathrm{v} / \mathrm{v} \% \mathrm{~N}_{2}$ content; (b) imaginary part of the dielectric function for the low absorption spectral range (solid curve) and artifacts caused by slightly increasing and decreasing the thickness of the roughness layer (dotted and dashed curves) with respect to the optimum; (c) real part of the dielectric function calculated by numerical inversion (solid black) and Kramers-Kronig integration (dashed gray) for the optimum film and surface roughness thicknesses; the corresponding normalized self consistency curve is shown in the inset; (d) RMS values of the SCCs, mapped as the function of surface roughness and film thickness; the optimum is marked by the $\mathrm{X}$. 

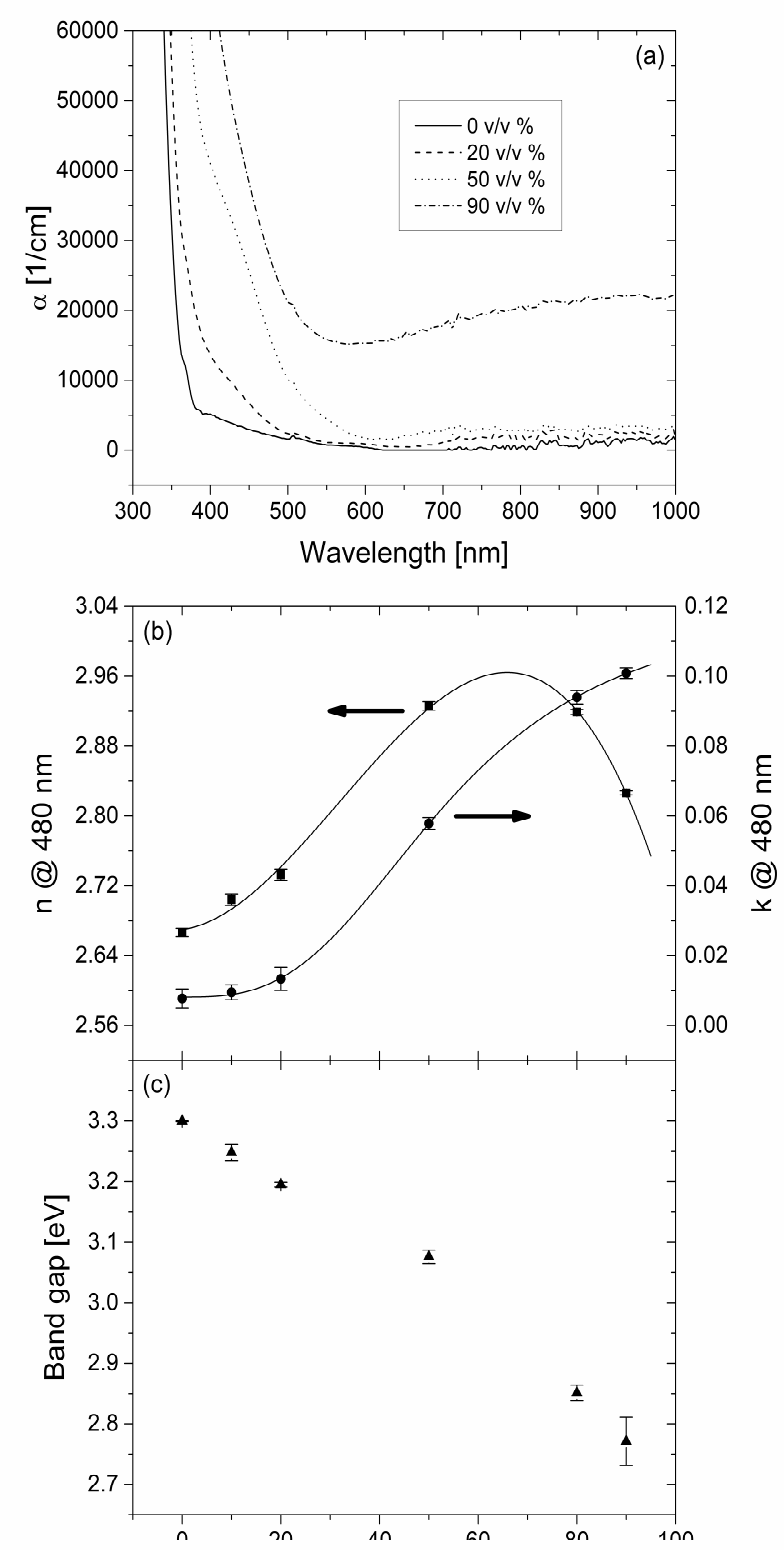

Fig. 2. The effect of $\mathrm{N}_{2}$ concentration in the processing gas mixture on the (a) absorption coefficient, (b) refractive index and extinction coefficient (solid lines are only guides to the eye) and (c) band gap of the grown layers. 

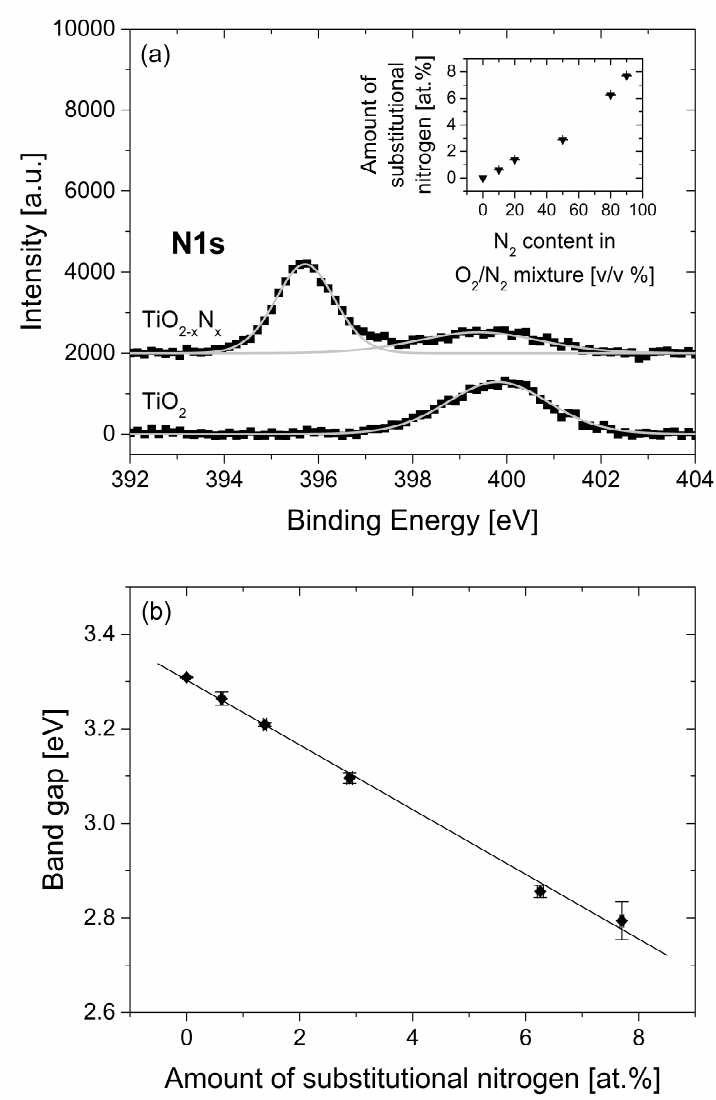

Fig. 3. (a) High resolution $\mathrm{N}$ 1s XPS spectra for the films deposited at $330^{\circ} \mathrm{C}$ substrate temperature in pure oxygen atmosphere and in a gas mixture of $90 \mathrm{v} / \mathrm{v} \% \mathrm{~N}_{2}$ content. The inset shows the amount of substitutional $\mathrm{N}$ in the grown layers as a function of the $\mathrm{N}_{2}$ content of the $\mathrm{N}_{2} / \mathrm{O}_{2}$ gas mixture; (b) band gap values as a function of the amount of substitutional $\mathrm{N}$. 


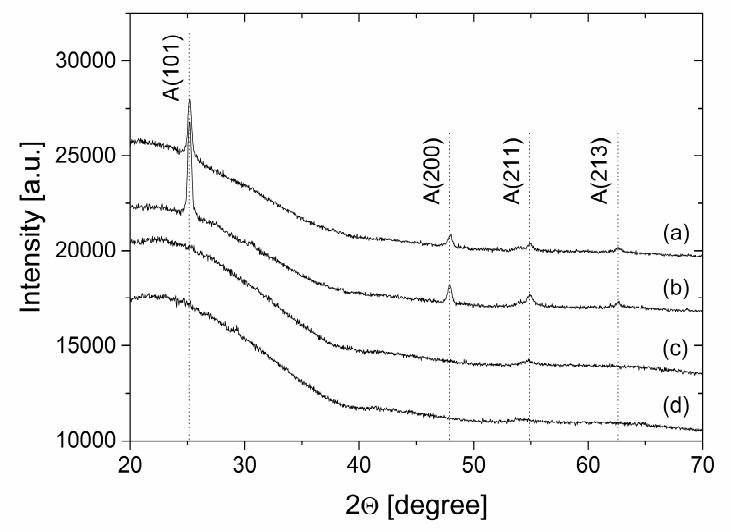

Fig. 4. XRD diffractograms of the films deposited at $330^{\circ} \mathrm{C}$ substrate temperature in different $\mathrm{N}_{2}+\mathrm{O}_{2}$ gas mixtures containing (a) 0 , (b) 20 , (c) 50 and (d) $90 \mathrm{v} / \mathrm{v} \% \mathrm{~N}_{2}$. 